\title{
Pengaruh Etika Kerja Islam terhadap Kinerja Karyawan BAZNAS Kota Bandung
}

\author{
Yeni Haryati*, Mohamad Andri Ibrahim \\ Prodi Hukum Ekonomi Syariah, Fakultas Syariah Universitas Islam Bandung \\ Bandung, Indonesia \\ *yeni.haryati0409@gmail.com, andri.ibrahim@gmail.com
}

\begin{abstract}
The Islamic work ethic can be defined as a guideline regarding the beliefs that exist within a Muslim that work is not merely to fulfill needs but as a means of worshiping Allah SWT. This study will review the extent to which the implementation of Islamic work ethics in Baznas Bandung. The research method used is quantitative with a survey approach. Data collection techniques use questionnaires. Data analysis using simple regression analysis and data processing through SPSS software. The result of this study is that there is a positive influence between the variables of Islamic work ethics and employee performance, meaning that if employees apply Islamic work ethics in their work, the quality of employee performance will increase.
\end{abstract}

Keywords: The Islamic work ethic, Employee Performance

\begin{abstract}
Abstrak. Etika kerja Islam dapat di definisikan sebagai pedoman mengenai keyakinan yang ada dalam diri seorang muslim bahwa bekerja bukan semata - mata untuk memenuhi kebutuhan tetapi sebagai sarana beribadah kepada Allah SWT. Pada Penelitian ini akan meninjau sejauh mana implementasi etika kerja islam di Baznas Bandung. Metode penelitian yang digunakan adalah kuantitatif dengan pendekatan survey. Teknik pengumpulan data menggunakan dengan penyebaran quesioner. Analisis data menggunakan analisis regresi sederhana dan pengolahan data melalui software SPSS. Hasil dari penelitian ini adalah adanya pengaruh positif antara variabel etika kerja Islam dan terhadap kinerja karyawan, artinya apabila karyawan menerapkan etika kerja Islam dalam setiap pekerjaannya maka kualitas dari kinerja karyawan akan semakin meningkat.
\end{abstract}

Kata Kunci: Etika Kerja Islam, Kinerja Karyawan 


\section{A. Pendahuluan}

BAZNAS Kota Bandung merupakan salah satu entitas syariah yang semua karyawannya beragama Islam sehingga sudah menjadi keharusan bagi karyawan BAZNAS Kota Bandung untuk menjadikan agama sebagai guiding principle dalam bekerja salah satunya dengan menerapkan etika kerja Islam.[1] Namun, berdasarkan interview dengan salah satu karyawan BAZNAS Kota Bandung terkait dengan kelalaian dalam bekerja faktanya terdapat beberapa karyawan BAZNAS Kota Bandung yang menggunakan waktu kerjanya untuk melakukan kegiatan pribadi. Hal tersebut dikhawatirkan berpengaruh terhadap kinerja karyawan BAZNAS Kota Bandung karena salah satu indikator penilaian kinerja adalah dapat memanfaatkan waktu kerja secara optimal.[2] Sehingga, perlu dilakukan analisis mengenai kinerja karyawan, salah satunya dengan mengetahui pengaruh etika kerja Islam. [3] Berdasarkan uraian dari latar belakang di atas, maka perumusan masalah dalam penelitian ini sebagai berikut:

1. Bagaimana sistem penilaian kinerja karyawan di BAZNAS Kota Bandung?

2. Bagaimana pengaruh etika kerja Islam terhadap kinerja karyawan BAZNAS Kota Bandung?

Selanjutnya, tujuan dalam penelitian ini diuraikan dalam pokok-pokok sebagai berikut.

1. Untuk mengetahui sistem penilaian kinerja karyawan di BAZNAS Kota Bandung

2. Untuk mengetahui pengaruh etika kerja Islam terhadap kinerja karyawan di BAZNAS Kota Bandung

\section{B. Metodologi}

\section{Pendekatan Penelitian}

Penelitian ini adalah penelitian kuantitatif dengan pendekatan survey dimana peneliti melakukan interaksi langsung ke lapangan untuk memperoleh data penelitian. pada penelitian ini pendekatan survey digunakan untuk mengetahui pengaruh etika kerja islam yang dapat diarahkan pada meningkatnya kinerja karyawan BAZNAS Kota Bandung dengan menyebar kuesioner kepada karyawan BAZNAS.

\section{Jenis Data Penelitian}

Jenis data yang digunakan adalah data lapangan. Data lapangan adalah data yang diperoleh oleh peneliti dalam melakukan interaksi langsung dengan pihak - pihak yang berkaitan dengan objek penelitian tersebut.[4] Data lapangan dalam penelitian ini diperoleh dengan menyebarkan kuesioner kepada karyawan BAZNAS Kota Bandung.

\section{Sumber data Penelitian}

Sumber data di peroleh dari data Primer dan Sekunder, data primer di peroleh langsung dari hasil wawancara dengan kepala divisi Sumber Daya Manusia dan Adminstrasi Umum, serta kuesioner yang disebarkan keseluruh karyawan BAZNAS Kota Bandung. Sedangkan data sekunder diperoleh dari buku, jurnal, tesis, dokumen - dokumen BAZNAS Kota Bandung serta website BAZNAS Kota Bandung.

\section{Teknik Pengumpulan Data}

Dalam penelitian ini menggunakan dua jenis teknik pengumpulan data, yang pertama adalah kuesioner, yang kedua adalah wawancara terstruktur.

\section{Teknik Analisis Data}

Pada penelitian ini menggunakan teknik analisis data berupa uji validitas, uji reliabilitas, uji hipotesis dan analisis regresi sederhana.

\section{Hipotesis}

Hipotesis dalam penelitian ini adalah sebagai berikut:

Ho = Etika kerja Islam tidak berpengaruh terhadap kinerja karyawan 
$\mathrm{Ha}=$ Etika kerja Islam berpengaruh terhadap kinerja karyawan

\section{Pembahasan dan Diskusi}

1. Sistem Penilaian Kinerja Karyawan di BAZNAS Kota Bandung

Sistem penilaian di BAZNAS Kota Bandung menggunakan sistem Bottom Up atau penilaian yang dilakukan oleh atasan 1 dan atasan 2 dan termasuk kedalaman bidang garapan SDM Administrasi dan Umum, BAZNAS Kota Bandung menetapkan dua indikator dalam penilannya terhadap karyawan yang meliputi: kemampuan dan perilaku / relationship budaya kerja. Mekanisme penilaian di BAZNAS Kota Bandung yaitu dengan mengisi "Form Daftar Penilaian Perfoma Pegawai" yang berbentuk buku yang bagikan ke atasan dari masing - masing bidang sebagai penilai pertama, setelah itu diberikan ke wakil ketua 4 untuk dilakukan konversi sesuai dengan skor yang telah ditetapkan oleh BAZNAS Kota Bandung

2. Pengaruh Etika Kerja Islam terhadap Kinerja Karyawan

Penelitian ini menggunakan instrumen kuisioner yang terdiri dari 7 pernyataan untuk variabel X (etika kerja Islam) dan 6 pernyataan untuk variabel Y (kinerja karyawan). Jumlah keseluruhan pernyataan adalah 13 pernyataan. Untuk mencari seberapa besar pengaruh etika kerja Islam yang diterapkan oleh karyawan BAZNAS Kota Bandung terhadap kinerja karyawan, maka dapat dilihat dengan menggunakan persamaan regresi sebagai berikut:

$Y=a+\beta x$

Hasil perhitungan koefisien regresi dilakukan menggunakan SPSS dan diperoleh hasil sebagai berikut:

Tabel 1. Analisis Regresi Sederhana

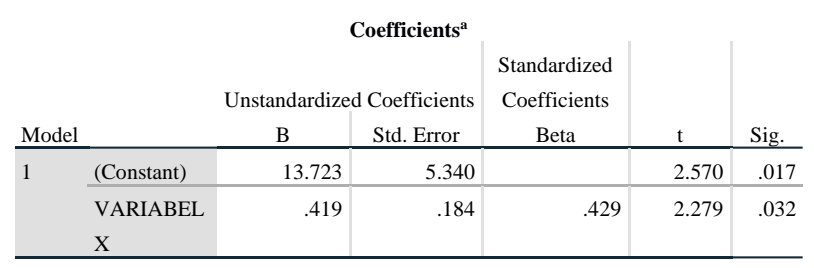

Pada tabel 1 maka diperoleh persamaan sebagai berikut:

1. Nilai konstanta (Y) sebesar 13,723, artinya jika variabel etika kerja Islam (X) nilainya adalah 0 (nol), maka variabel kinerja karyawan (Y) bernilai 13,723.

2. Koefisien $X$ (etika kerja Islam) sebesar 0,419. Hal tersebut menunjukan bahwa variabel etika kerja Islam berpengaruh positif dan signifikan terhadap perilaku konsumen Islami, dengan kata lain jika variabel etika kerja Islam ditingkatkan sebesar satu, maka variabel kinerja karyawan akan meningkat 0,419

Selain itu, pengujian individual (Uji t) dalam penelitian ini memperoleh hasil bahwa variabel etika kerja Islam mendapatkan nilai t hitung sebesar 2,279 sedangkan nilai t tabel sebesar 2,073. Dengan demikian t hitung $(2,279)>t$ tabel $(2,073)$ dan nilai signifikansi sebesar $0,032<0,05$. Sehingga dapat diambil simpulan bahwa etika kerja Islam berpengaruh positif signufikan terhadap kinerja karyawan.

Untuk mengukur seberapa besar kemampuan model dalam menerangkan variabel terikat terhadap penelitian ini maka digunakan koefisien korelasi $(\mathrm{R})$ dan pengaruh variabel bebas terhadap variabel terikat ditunjukkan oleh koefisien determinasi (KD) [5]. Hasil perhitungan hubungan serta pengaruh variabel $\mathrm{x}$ terhadap variabel $\mathrm{y}$ dapat dilihat pada tabel berikut: 
Tabel 2. Uji Koefisien Determinasi

\begin{tabular}{|c|c|c|c|c|c|}
\hline \multirow[b]{2}{*}{ Model } & \multicolumn{4}{|c|}{ Model Summary } & \multirow[b]{2}{*}{ Durbin-Watson } \\
\hline & $\mathrm{R}$ & R Square & $\begin{array}{c}\text { Adjusted R } \\
\text { Square } \\
\end{array}$ & $\begin{array}{c}\text { Std. Error of the } \\
\text { Estimate }\end{array}$ & \\
\hline 1 & $.429^{\mathrm{a}}$ & .184 & .149 & 3.240 & 2.403 \\
\hline
\end{tabular}

Berdasarkan hasil uji koefisien determinasi, diketahui besarnya koefisien determinasi ( $R$ Square) etika kerja Islam adalah 0,184 atau $18,4 \%$. Hal ini menunjukkan bahwa $18,4 \%$ variabel etika kerja Islam oleh variabel kinerja karyawan sedangkan sisanya $81,6 \%$ dipengaruhi oleh variabel lain yang tidak dibahas dalam penelitian ini.

\section{Kesimpulan}

Berdasarkan hasil penelitian tentang "Pengaruh Etika Kerja Islam terhadap Kinerja Karyawan Baznas Kota Bandung", dapat ditarik kesimpulan sebagai berikut:

1. Sistem penilaian kinerja karyawan di BAZNAS Kota Bandung dilakukan sebanyak $2 x$ dalam setahun dengan sistem Bottom up yang merupakan garapan dari divisi SDM Administrasi dan Umum. Penilaian dilakukan dengan 2 instrumen yang berbeda yakni kemampuan yang terdiri dari 4 indikator dan perilaku / relationship budaya kerja yang terdiri dari 5 indikator penilaian. Hasil dari penilaian kinerja karyawan ini digunakan sebagai acuan bagi atasan untuk menetapkan kenaikan gaji, promosi jabatan, perpanjangan kontrak, pengangkatan karyawan tetap, reposisi, pemutusan hubungan kerja, pelatihan serta usulan karir bagi karyawan yang bersangkutan.

2. Terdapat pengaruh yang signifikan antara variabel etika kerja Islam terhadap kinerja karyawan Hal tersebut dibuktikan dari hasil analisis data bahwa etika kerja Islam berpengaruh positif terhadap kinerja karyawan, artinya apabila karyawan menerapkan etika kerja Islam dalam setiap pekerjaannya maka kualitas dari kinerja karyawan akan semakin meningkat. Kontribusi dari variabel $\mathrm{X}$ yaitu etika kerja islam terhadap variabel Y yaitu kinerja karyawan Baznas Kota Bandung yaitu 18,4\%. Sedangkan sisanya sebesar $81,6 \%$ perubahan yang terjadi pada varibel $\mathrm{Y}$ atau bentuk kinerja kerja karyawan disebabkan oleh faktor lainnya yang tidak diteliti selain daripada penerapan etika kerja Islam yang dilakukan oleh karyawan Baznas Kota Bandung.

\section{ACKNOWLEDGE}

Penulis mengucapkan banyak terimakasih kepada para dosen pembimbing satu dan dua yang senantiasa membimbing saya hingga penelitian ini selesai.

\section{Daftar Pustaka}

[1] M. Bisri, Mencari Bening Mata Air. Jakarta: Kompas Media Nusantara, 2008.

[2] Muhammad, Etika Bisnis Islami. Yogyakarta: Unit Penerbit dan Percetakan Akademi Manajemen Perusahaan YKPN, 2004.

[3] M. A. Ibrahim, N. Eprianti, and A. Yusup, "Selection of Priority Needs for Employee Recruitment in Islamic Banking," in 2nd Social and Humaniora Research Symposium (SoRes 2019), 2020, pp. 365-368.

[4] R. M. Putri, M. A. I, I. Siti, and R. Maulida, "Pengaruh Pelaksanaan Pengawasan Quality Assurance terhadap Kinerja Karyawan Di BPRS Al Salaam Cabang Kota Bandung," pp. 765-768.

[5] D. Mashudi, M. A. Ibrahim, and F. Ilahi, "The Effect of Macroeconomic Variables on Sharia Stock Prices in the Jakarta Islamic Index," vol. 409, no. SoRes 2019, pp. 324-327, 2020, doi: 10.2991/assehr.k.200225.068. 